\title{
Practical handbook for small-gauge vitrectomy, U. Spandau, H. Heimann
}

\author{
2013, ISBN: 978-3-642-23293-0 e-ISBN: 978-3-642-23294-7 Springer
}

\section{Bernd Kirchhof}

Received: 11 November 2013 / Accepted: 13 November 2013/Published online: 30 November 2013

(C) Springer-Verlag Berlin Heidelberg 2013

This is an excellent, hands-on manual for vitrectomy, written by two experienced vitreo-retinal surgeons.

The restriction in title to "small gauge" signifies the fact that most of the modern vitrectomy techniques nowadays are possible via trocar-guided micro-incisions. With regard to content, the emphasis of this booklet fortunately is not so much the access to the vitreous, but the complex surgical techniques within the vitreous cavity.

The hardback provides 12 chapters in 186 pages. It is an English translation of a 2009 monograph by Ulrich Spandau. The illustrations and the intraoperative fundus pictures are very instructive. Pictures of surgical tools are referenced with company names and purchase order numbers. The added DVDs of edited surgical procedures are of excellent quality and are narrated.

The strength of the book is the structured and systematic step-by-step instruction to vitrectomy, aimed at the beginner. Learning is fostered by 60 "pits and pearls" and by warnings of risks for complications. The complete coverage deserves recognition.
The book is certainly worth reading for beginners and experienced surgeons alike. I do not know of any other manual in the field that is as complete as this booklet.

The merits of micro-incision surgery are sometimes overdone. It neither renders trocar-guided vitrectomy "much safer and less traumatic", as mentioned in the preface, nor is it the advent of bimanual surgery, nor does it reduce overall surgery time, as shown by Susanne Binder (2008, BJO). It's value comes down to easier-to-find sclerotomies, no extensive opening of the conjunctiva, a closed system, and reduced postoperative, foreign body sensations.

The only true error I found was on page 28: heavy oils are a mixture of silicone oils with semi-fluorinated fluorocarbons, while perfluorocarbon liquids do not dissolve in silicone.

I would wish that the surgical experience conveyed here be available to a wider public than the buyers of this book-for example, in open access platforms such as Eyetube, Youtube, or Eyemoviepedia videos that can be found via a Google search.

Conflict of interest None
B. Kirchhof $(\bowtie)$

Zentrum für Augenheilkunde, Abt. für Netzhaut- und

Glaskörperchirurgie, Kerpenerstr. 62, 50937 Köln, Germany

e-mail: BeKirchhof@googlemail.com 